\title{
Dioses útiles. Naciones y nacionalismos
}

Salvador Lima*

Università di Bologna, Italia

salvador.lima.89@gmail.com

José Álvarez Junco, Dioses útiles. Naciones y nacionalismos, Barcelona, Galaxia Gutenberg, 2016, 316 pp. ISBN 978-84-17088-92-7

El nacionalismo es un concepto histórico y político cuyo tratamiento académico ha sufrido grandes transformaciones desde la segunda mitad del siglo XX. En Dioses útiles. Naciones y nacionalismos, José Álvarez Junco ofrece un ensayo de reflexión con la finalidad de contribuir a la difusión del conocimiento sobre las múltiples ideas y experiencias que han moldeado la evolución del nacionalismo como teoría, relato histórico y programa político. Como el propio autor lo reconoce, la obra no pretende presentarse como una investigación original, sino como una síntesis de conceptos, datos y conclusiones ya publicados por él mismo y por otros autores. El libro no trabaja sobre fuentes directas, ni ofrece novedades epistemológicas para los estudios del nacionalismo o los casos expuestos, por lo tanto, sus exposiciones pueden resultar un tanto repetitivas y ya conocidas para el público académico especializado. De hecho, el propio autor advierte esta posibilidad y asegura que su propuesta es

* Máster en Relaciones Internacionales. Grupo de Estudios en Historia de la Guerra, Universidad de Buenos Aires/CONICET, Argentina.

(c) (i) (8)

4.0 Internacional

Secuencia. Reseñas, 2021

http://secuencia.mora.edu.mx
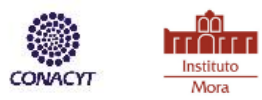


\section{Salvador Lima}

presentar las contribuciones de las ciencias sociales e insertar en su marco teórico la trayectoria de ciertos nacionalismos relevantes en Europa y las Américas, a través de la historia comparada y un enfoque general. De este modo, busca explicar al público general las características comunes y diferenciales en los procesos de construcción de la nación, demostrando su desarrollo temporal y despejando la tentación teleológica. El libro se articula en torno a dos ideas centrales. La primera es de carácter conceptual y es la afirmación de que toda identidad nacional es una construcción histórica, un resultado de procesos sociales, políticos y culturales, y que, por ende, no existe tal cosa como el espíritu colectivo del pueblo, ni el genio nacional. De este modo, ningún caso nacional es especial, todos son explicables, recurriendo a los mismos conceptos. Vinculado a esto último, la otra idea principal es de índole metodológica y refiere a la historia comparada. Según Álvarez Junco, éste es el método idóneo para demostrar la naturaleza histórica de la nación. La comparación permite tomar distancia emocional de cada caso y contrastar unos con otros de manera racional, rechazando las explicaciones esencialistas.

El autor desarrolla estas dos premisas principales en el primer capítulo, en el cual explica lo que él llama la "revolución científica sobre los nacionalismos". Después de las catástrofes producidas por los regímenes fascistas, los intelectuales occidentales utilizaron las herramientas de las ciencias sociales para desarrollar otra forma de explicar el surgimiento de las naciones. La historiografía marxista británica, la sociología de la movilización social y el giro lingüístico han permitido llegar a la conclusión que los actores históricos se mueven en una realidad que perciben a través de instrumentos culturales creados por el grupo social en el que 
viven y que ellos perciben como inmutable, pero que resulta fluida y dinámica. Esta nueva manera de entender las identidades convierte a las naciones en objetos históricos, mientras que para la historiografía decimonónico eran sujetos, los grandes protagonistas. Álvarez Junco toma partido por esta perspectiva constructivista o modernista, la cual ha sido predominante en las ciencias sociales desde los años 1950s y expone las ideas principales de sus grandes teóricos, como Anthony Smith, Ernest Gellner, Benedict Anderson y Eric Hobsbawn. De acuerdo con el historiador español, los constructivistas del nacionalismo han logrado una aceptación casi absoluta entre los investigadores y universidades, a tal punto que la visión primordialista de la nación, típica de las historias nacionales del siglo XIX y de la primera mitad del XX, ha quedado prácticamente descartada. El consenso indica que la nación es un artefacto cultural y político, construido por los Estados europeos en el siglo XIX, luego de las revoluciones antiabsolutistas que destruyeron los antiguos fundamentos de la legitimidad e hicieron necesarios crear un nuevo principio ordenador. Éste sería la soberanía nacional, basada sobre un cuerpo de ciudadanos pertenecientes a la misma comunidad imaginada, teóricamente portadores comunes de un conjunto de tradiciones y características étnicas, y habitantes de un mismo territorio. Ahora bien, aunque Álvarez Junco adhiere a la premisa elemental de que toda nación es una construcción histórica, no está dispuesto a admitir que sean invenciones creadas sobre la nada y perfectamente instrumentalizadas por motivos políticos. El historiador español afirma que, para la construcción de la nacionalidad tenga efectos perdurables, debe asentarse sobre rasgos culturales preexistentes. Construida sobre tradiciones, símbolos, gestas, héroes y memorias colectivas, la nación cobra sentido para el más común de los E-ISSN 2395-8464 
ciudadanos, confiriéndole derechos políticos y obligaciones para con el nuevo Estado-nación.

A partir del segundo capítulo, Álvarez Junco analiza los casos de los nacionalismos europeos y de otras naciones relacionadas o influenciadas por ellos, como Rusia, Turquía, Estados Unidos y las repúblicas de América Latina. La elección por estos casos no se debe solamente a que son los más conocidos y mejor estudiados, sino también a que fue en Europa y en las Américas, donde se forjaron los modelos nacionales imitados más tarde por los movimientos de la descolonización en África y Asia. El capítulo es básicamente un resumen de la historia europea y de su marco geopolítico, que comienza por los principados feudales y las ciudades-Estado de la Edad Media, aplicando los conceptos del constructivismo para demostrar el proceso de construcción de cada nacionalidad y negar los preceptos primordialistas de los nacionalistas. Considerando que la intención confesada del autor es explicar al público general la construcción de las naciones, el capítulo es eficaz. Con todo, parecería que el ejercicio de la comparación debe ser realizado por el propio lector, ya que Álvarez Junco se limita a exponer de manera individual la historia política de los países seleccionados. Dicho esto, al lector especializado, el capítulo podría parecerle una simple narración histórica poco original.

El tercer capítulo del libro aborda una de las cuestiones que más le preocupan a Álvarez Junco: la explicación de la historia y de los fundamentos del nacionalismo español. La estructura que utiliza para exponer la construcción de España es exactamente la misma que la que aplica en los casos anteriores. El objetivo del autor es doble. Por un lado, explicar la construcción política, social y cultural de la 
nacionalidad española, como parte de un proceso histórico que comienza con los Reyes Católicos y llega hasta la Transición, demostrando sus similitudes y diferencias con los otros casos europeos, para descartar el tan arraigado mito de la excepcionalidad española. Al mismo tiempo, Álvarez Junco debate contra la idea falaz que España es una invención política artificial, como afirman muchos ensayistas extranjeros y los políticos nacionalistas del independentismo catalán y vasco, así como contra la visión tradicional de la derecha franquista, que cree ver en la nacionalidad española un espíritu colectivo inmutable y esencial que se remonta a la noche de los tiempos. Para reforzar su argumento de la historicidad de España, el autor dedica el último capítulo a lo que llama las "identidades alternativas de la península Ibérica”. Sorprendentemente, además de concentrarse en los casos obligados de Cataluña, País Vasco, Galicia y Portugal, también incluye la elaboración de la identidad andaluza como una suerte de regionalismo, sin nacionalismo. La comparación entre los casos ibéricos trata de exponer la naturaleza contingente de sus procesos de formación política en relación con España, demostrando que ni la secesión portuguesa, ni las construcciones tardías del catalanismo y vasquismo tuvieron fundamento orgánico o espiritual, sino que fueron consecuencia de hechos sociales y de la voluntad de ciertas elites. De este modo, el autor busca desmitificar las narrativas esencialistas que tergiversan la historia de España para legitimar los intentos separatistas.

Para concluir, Dioses útiles. Naciones y nacionalismos puede no ser un aporte original al conocimiento científico y puede resultar repetitivo para el público académico, pero es una gran obra de reflexión erudita, que será de utilidad para 
estudiantes, aficionados a la historia e, incluso, para historiadores que deseen contar con una síntesis completa sobre el marco teórico acerca del nacionalismo. De manera clara y accesible, Álvarez Junco logra exponer y contrastar las diferentes teorías primordialistas y constructivistas, además de explicar de manera eficaz los casos de construcción nacional más relevantes de Europa y las Américas. 